\title{
BIOÉTICA Y RECIPROCIDAD EN EL RECONOCIMIENTO DE DERECHOS Y DEBERES
}

\author{
Raúl Villarroel Soto*
}

\begin{abstract}
Resumen: Desde una perspectiva hermenéutica, se analiza el estatuto de la medicina en tanto arte de curar, considerando su particular característica de techne y sus diferencias con los demás saberes técnicos productores de obras. Esta dificultad se ve complejizada por la irrupción de las implementaciones técnicas y cambios morales en la modernidad, que amenazan su praxis efectiva y ponen en riesgo su identidad esencial. Hoy se entiende que la Medicina es más que el puro ejercicio de técnicas y saberes especializados, y que toda intervención médica responsable debe ajustarse al espacio de reconocimiento de aquella compleja y esencial multidimensionalidad de lo humano, inaprehensible para cualquier esfuerzo meramente explicativo o técnico que intente contemplar su vastedad y pluralidad.
\end{abstract}

Palabras clave: arte de curar, relación médico-paciente, derechos y deberes de los pacientes, bioética, hermenéutica

\section{BIOETHICS AND RECIPROCITY IN THE ACKNOWLEDGEMENT OF RIGHTS AND DUTIES}

Abstract: From a hermeneutic perspective, this article analyzes the statute of medicine as a healing art, considering its particular technical characteristic and its differences with other technical knowledge that delivers goods. This difficulty is compounded by the eruption of technical implementations and moral changes of modernity, which threaten effective practice and places its essential identity at risk. Currently it is understood that Medicine is more than the mere application of techniques and specialized knowledge, and that all responsible medical interventions should adjust their definition to the complex and essentially multidimensional nature of human beings, which is not realized by mere technical explanations or techniques that attempt to envision its vastness and plurality.

Key words: art of healing, doctor-patient relationship, rights and duties of patients, bioethics, hermeneutics

\section{BIOÉTICA E RECIPROCIDADE NO RECONHECIMENTO DE DIREITOS E DEVERES}

Resumo: A partir de uma perspectiva hermenêutica, analisa-se o estatuto da medicina enguanto arte de curar, considerando sua característica particular de techne e suas diferenças com os demais saberes técnicos produtores de obras. Esta dificuldade torna-se mais complexa com a irrupção das implementaçóes técnicas e mudanças morais na modernidade, que ameaçam sua praxis efetiva e colocam em risco sua identidade esencial. Hoje se entende que a Medicina é mais que o puro exercício de técnicas e saberes especializados, e que todas intervenção médica responsável deve se ajustar ao espaço de reconhecimento da complexa e esencial multidimensionalidade do humano, inapreensible em qualquer esforço meramente explicativo ou técnico que procure contemplar sua vastidão e pluralidade.

Palavras chave: arte de curar, relação médico-paciente, direitos e deveres dos pacientes, bioética, hermenêutica

\footnotetext{
Magíster en Bioética. Doctor en Filosofía. Director del Centro de Estudios de Ética Aplicada de la Facultad de Filosofía y Humanidades, Universidad de Chile

Correspondencia: rvillarr@uchile.cl
} 


\section{Bioética y hermenéutica en el arte de curar}

Atendiendo al peculiar carácter que identifica a la medicina, en tanto ésta no responde enteramente a aquello que los griegos llamaron alguna vez techne (término traducido posteriormente como arte o ciencia), Hans-Georg Gadamer da cuenta de la transformación del concepto griego y su aplicación al ámbito de la medicina, operación mediante la cual se habría establecido una cuestión decisiva para la civilización occidental: el hecho de que el médico abandona la figura del curandero para adquirir la fisonomía del hombre de ciencia. Aristóteles justamente ilustraría, a través del ejemplo de la medicina, la transformación de lo que era una simple acumulación de habilidad y saber en una verdadera ciencia(1).

El médico entiende la razón del éxito de una determinada intervención terapéutica porque puede comprender también la relación entre causas y efectos. Sin embargo, en este caso no se trataría de la simple aplicación de unos principios a unos fines prácticos, como el de la curación, por ejemplo -lo que nos pondría de inmediato ante la caracterización metódica de la ciencia moderna-, porque la techne griega no consiste en la simple aplicación práctica de saberes teóricos, sino que constituye una forma propia de conocimiento: el conocimiento técnico, definido por la capacidad de producir una obra, un ergon.

$\mathrm{Al}$ interior de este particular concepto de arte (o ciencia), la medicina ocupa un lugar especial y no exento de dificultades. Porque en su caso no hay una obra "artística", ni tampoco ella trabaja con un material dado en la naturaleza que pueda transmutarse para obtener tal obra, como sí ocurre en otros saberes técnicos. "La esencia del arte de curar consiste, más bien, en volver a producir lo que ya ha sido producido". Por lo mismo, sería inexacto sostener que el médico produce salud, si quisiéramos referirnos de este modo a un cierto ergon resultante de su capacidad productiva; puesto que, más bien, el restablecimiento de la salud del enfermo es sólo parcialmente atribuible a la intervención del médico, ya que resulta imposible afirmar exhaustivamente la total ausencia de otras razones que hayan colaborado a ello, incluso aunque no se tenga certeza de cuánto pueda haber colaborado la misma naturaleza(1:47). Una cuestión semejante habría que pensar de la situación de fracaso terapéutico. Idéntico reparto causal parece posible entre unos factores naturales, imponderables o destinales, y la impericia o incapacidad de la acción médica como tal para restaurar el estado de equilibrio natural de la salud perdida.

Ahora bien, en la medicina moderna se manifiesta un problema que puede alcanzar un significado decisivo para nuestra época. El exponencial desarrollo de su tecnificado quehacer actual le ha ido imprimiendo un cierto perfil fundamentalista. Su pretensión de conocer y avanzar sin medida respecto de la enfermedad le hace perder de vista, a veces, la dimensión más propiamente humana y esencial de las personas. En ocasiones parece olvidar también la emoción y la intuición, la palabra y el símbolo, la esperanza y el sentido profundo de la experiencia humana. Así, puede perder de vista aquel núcleo existencial sobre el que repercute de una manera particular y aún no suficientemente conocida la salud, abriendo o cerrando el mundo con su presencia $o$ ausencia.

Frente al efecto desintegrador del individuo desencadenado por el dispositivo técnico, la responsabilidad médica debe ir más allá de la simple "contabilidad" de síntomas o valores específicos que hacen visible al paciente y lo ajustan a criterios estadísticos. La medicina debe mantener a la vista y a buen recaudo el valor personal, individual e intransferible de cada paciente. Se manifiesta de este modo la distancia entre la perspectiva objetivizante -basada en el experimento y el cálculo- y un verdadero arte de curar, que comprende que su éxito no es deudor de sí mismo sino de la naturaleza inefable y de la vida que puede restablecerse y reincorporarse a partir de ella misma. Porque el cúmulo de información que la ciencia moderna puede ofrecer respecto del hombre, en relación con cualquiera de sus aspectos, no debe ser escindido de los intereses prácticos del propio hombre(1:29).

Ello constituye parte esencial de la salud, que no admite valores provenientes de estandarizaciones establecidas a partir de promedios derivados de la experimentación. Una imposición de este tipo siempre será inapropiada para el caso individual. Se puede pensar que la salud corresponde, más que a patrones convencionales de medición, a una medida interna, de coincidencia del enfermo con su propio ser, con sus proyecciones de sentido, con sus esperanzas de vida plena. El médico es alguien que colabora en algo que la misma naturaleza realiza. La salud corresponde a un ritmo que es propio de la vida misma, pensada como un proceso de conti- 
nuidad en el que un equilibrio se está restableciendo permanentemente. Por ello, la salud es una forma de ser-en-el-mundo.

En efecto, la medicina se enfrenta a una situación difícil que la impulsa a ser mal comprendida cuando en su quehacer prevalecen los dispositivos tecnológicos modernos. La tarea del profesional se limita con ello a un nivel de exclusiva competencia técnico-científica, ensombreciéndose una dimensión más amplia de su ser y su quehacer. Aunque habría que advertir que, con frecuencia, es el propio estado deprivado y mórbido del paciente el que termina distorsionando la situación global de la relación sanitaria. Y es que, ante la angustia experimentada por la pérdida de salud, el paciente reduce su percepción y centra sus expectativas en el despliegue técnico. Desconoce así la importancia de otros factores inherentes también al acto médico, otras responsabilidades, otras dimensiones humanas y sociales amplias que resultan tan fundamentales como aquellas que lo interpelan desesperadamente ante su urgencia y necesidad.

Sin embargo, han acontecido cambios en la comprensión del vínculo entre el médico y el paciente. El propio surgimiento de la bioética trajo consigo un rediseño de este complejo horizonte de interacción. En su cometido integrador, en su perspectiva unificante de conocimiento y valor en pos de una mejor reflexión acerca de la instrumentalización de la vida por parte del saber científico, la bioética ha operado un nuevo reparto normativo entre médicos y pacientes. El viejo problema teórico de una eventual y problemática articulación entre lo axiológico y lo epistemológico ha pasado a ser también asunto de la práctica(2). Por eso, hoy se entiende que la medicina es mucho más que el puro ejercicio de técnicas y saberes específicos; ella se mueve en medio del estrecho corredor que separa el conocimiento propio de las ciencias - que avanzan sobre la naturaleza para dominarla- del inefable misterio de la realidad mental y espiritual de lo humano que enfrenta la enfermedad.

El complejo espectro de asuntos inherentes a la experiencia humana del padecimiento y el dolor resulta inabordable para el saber científico positivo. Estar enfermo es algo más que acusar síntomas; es vivir de una manera determinada la vida, en un curso paralelo, amenazante y desintegrador, inescrutable en sus más profundas dimensiones emocionales. No se puede admitir que de la enfermedad exista una única y verdadera interpretación (la de las ciencias biomédicas). Único es sólo el paciente, el individuo en una total diversidad. La hermenéutica de sus circunstancias, por tanto, siempre es múltiple y alberga comprensiones inesperadas.

Sea que se trate de restablecer la salud extinguida o de cuidar la que ya existe, siempre estará en juego una interpretación abierta de las condiciones. Ellas, a su vez, siempre pueden ser representadas en nuevos contextos y alumbrar nuevas soluciones. La medicina debe abrir espacios nuevos de comprensión radical del fenómeno de la enfermedad y abrir el diálogo con todas las voces que intervienen en su recuperación cuando la salud se ha perdido; debe mirar transversalmente el fenómeno de la vida, indagando en aquello que hasta ahora ha mantenido excluido como criterio de explicación fenoménica.

De esta manera, toda intervención médica responsable debe ajustarse siempre al espacio de reconocimiento de aquella compleja y esencial multidimensionalidad de lo humano, inaprehensible para cualquier esfuerzo meramente explicativo que intente contemplar su vastedad y pluralidad. La antigua dialéctica entre explicación y comprensión cobra en este caso especial relevancia. Ello podemos entenderlo como el aspecto central de la "responsabilidad" médica, como tarea ineludible del llamado a una hermenéutica integral del fenómeno de la vida.

\section{Fragmentación de la moral}

Por otra parte, sabemos que la fase actual de nuestra civilización está marcada por una transformación fundamental de los problemas. El tipo de sociedad articulada a partir de las nuevas condiciones generales, impuestas por el modelo de desarrollo técnico y económico vigente a partir de la segunda mitad del siglo anterior, ha desencadenado múltiples circunstancias conflictivas para la existencia de las personas, para sus relaciones, sus deberes y derechos, y sus necesidades y demandas. Los efectos del modelo de desarrollo puesto en obra durante las últimas décadas no siempre han sido favorables para los seres humanos y en reiteradas ocasiones se han constituido en una verdadera amenaza para sus vidas.

Aun cuando no se trate de un fenómeno eruptivo, reciente e insospechado -puesto que hunde sus raíces en la propia constitución de la época moderna-, en las actuales dimensiones se plantean desafíos hasta ahora 
inéditos, la mayor parte enmarcados en un ámbito de problemas en el que gravita críticamente la cuestión de los derechos. Éstos, al parecer, han llegado a convertirse en un eje de centralidad para la determinación de legitimidad de los parámetros con los que se escrutará el presente y se proyectará el futuro de la humanidad. En la actualidad, la temática referente a los derechos es clave ineludible de comprensión para la experiencia humana, prácticamente en todas sus dimensiones, y orienta marcadamente el desarrollo de una modalidad particular de resolución de las dificultades señaladas.

No resulta difícil comprender que el fortalecimiento de la cuestión de los derechos surge precisamente porque ninguna de las éticas anteriores podía orientar nuestro comportamiento o instruirnos respecto de los criterios que deben regir este nuevo poder tecnocientífico y orientar sus previsibles implicancias. Y ello porque ninguna tuvo la oportunidad de considerar condiciones de carácter global como las imperantes para comprender la vida humana, ni mucho menos las circunstancias y consecuencias que definirían o afectarían al futuro, todavía lejano entonces(3). Recién ahora estos asuntos empiezan a formar parte de la percepción de realidad del hombre y de su reflexión; ahora es cuando ellos exigen nuevas formulaciones relativas a los derechos $y$ los deberes de una humanidad que carece actualmente de principios $\mathrm{u}$ orientaciones ajustadas a la escala de sus actos presentes. Ello porque los problemas contemporáneos se plantean sobre el marco de fragmentación de la perspectiva moral, indisolublemente ligada al descrédito y los cambios ocurridos en el espacio de las convicciones éticas y ontológicas del mundo occidental; se trata de una verdadera revolución en contra del conjunto de ideas heredadas de otra época. Estos nuevos caracteres redefinen el horizonte de significación que procuraba la ética tradicional, tendiendo a reformar o a desintegrar de manera general los vínculos colectivos $\mathrm{y}$ las creencias.

En general, la cuestión de los derechos es compleja y difícil de abordar sin que en el intento irrumpan intereses diversos e interpretaciones locales que ponen de manifiesto graves y acuciantes problemas relativos al deber y a la ética; siempre es difícil establecer los mínimos necesarios y suficientes para que la relación entre los individuos -o entre las generaciones, como sería en el caso de los derechos ecológicos, por ejemplo- pueda considerarse justa y por tanto ética. En principio, podría considerarse inmoral todo acto que no sea universalizable y que, por tanto, beneficie a unos en perjuicio de otros, vale decir, que no dé muestras de mínima reciprocidad; porque en un mundo de relaciones como el nuestro se espera que todo sujeto de derechos soporte, por lo mismo, obligaciones o deberes morales que tienden a equilibrar la satisfacción de necesidades de cada uno.

Clarificar la cuestión de los deberes es otro asunto que igualmente se torna en extremo difícil hoy en día, porque el panorama evidencia una modalidad tan particular de enfrentarse con ellos que definirlos positivamente resultaría imposible. Pero, ¿qué son los deberes? ¿Qué entendemos por tales? ¿Poseen éstos un carácter absoluto? ¿Nos obligan siempre? Sin ir más lejos, y aunque este es un asunto que abordaremos más adelante, Gilles Lipovetsky caracterizó a la época presente como la era del posdeber, porque, a su juicio, repudia el deber austero, integral y maniqueo, pero paralelamente exalta los derechos individuales a la autonomía, al deseo y la felicidad, despojándose en su trasfondo de prédicas maximalistas y otorgando crédito sólo a aquellas normas indoloras de la vida ética(4).

\section{Deberes perfectos e imperfectos}

En la tradición antigua (Aristóteles, "Ética a Nicómaco") ya se distinguían con precisión dos tipos de deberes o preceptos: los negativos y los positivos, fórmula que, habiendo tenido continuidad durante la Edad Media, explicitaba que los preceptos negativos prohíben los actos pecaminosos mientras que los positivos alientan o inducen a la comisión de actos virtuosos (Santo Tomás, "Summa Theologica"). Los actos pecaminosos son en sí mismos malos y de ellos no puede resultar el bien de ningún modo, porque, de acuerdo con su naturaleza, se hallan unidos a un fin malo. Por ello entonces, según Aristóteles, los preceptos negativos obligan siempre y para siempre (obligan a no cometerlos). Por el contrario, los actos virtuosos no deben ejercitarse de cualquier modo sino sólo bajo las circunstancias requeridas para que lo sean; vale decir, obligan siempre, claro que no para siempre. Por tanto, si existiese una circunstancia que llegara a privar de bien al acto virtuoso éste contrariaría al precepto, luego no debería practicarse.

Posteriormente, en la tradición moderna la perfección o la imperfección de los deberes (preceptos negativos y positivos en términos escolásticos) estará referida sólo a la capacidad de que éstos sean o no exigibles coacti- 
vamente y dependerá de un rasgo característicamente moderno como es la distinción entre lo público y lo privado. Los deberes de justicia serán según esto perfectos; a saber, deben ser exigidos, aun coactivamente, a todos por igual. Por el contrario, los deberes de beneficencia (decoro y honestidad) serán imperfectos porque, estando remitidos a la gestión individual, no pueden ser impuestos al conjunto de la sociedad y sólo el sujeto puede imponerlos voluntariamente a sí mismo si así lo quiere.

Por ello, los deberes perfectos tienen un carácter público y le corresponde al Estado su gestión, en tanto que los deberes imperfectos, teniendo carácter privado, son de exclusiva competencia individual. En síntesis, la teoría de los deberes perfectos e imperfectos surge claramente como una derivación, adaptada a los nuevos parámetros históricos y sociales modernos, de la distinción escolástica (aristotélico-tomista) entre preceptos negativos y positivos; sin embargo, a pesar de sus modificaciones conceptuales y de la sustitución de su fundamentación natural por esta otra racional, sigue manteniendo un carácter absoluto. El principio central de que todos los preceptos son absolutos (los preceptos negativos obligan siempre y para siempre, los preceptos positivos obligan siempre, aunque no para siempre) sigue en pie, especialmente aquellos que durante el medioevo se denominaban negativos y ahora perfectos.

La culminación y la crisis de este desarrollo histórico se localizan en la filosofía de Kant ("Fundamentación de la Metafísica de las Costumbres"). La formulación del imperativo categórico corresponderá a una forma de legalidad racional que sustituye el antiguo orden de la ley natural de la filosofía escolástica, el cual ordenaba hacer el bien y evitar el mal. El imperativo categórico kantiano será universal y absoluto, al igual que el precepto naturalista, pero con un carácter formal y canónico, porque los principios morales de contenido material y carácter deontológico no pueden ser siempre absolutos.

Kant distingue, en efecto, dos tipos de principios deontológicos: los perfectos y los imperfectos. Los primeros son aquellos cuya conversión en una máxima universal no puede pensarse, ya que resulta intrínsecamente contradictoria. Los conocidos ejemplos del propio Kant al respecto se refieren al suicidio y a las falsas promesas. La máxima de quitarse la vida por egoísmo no podría pensarse sin contradicciones porque no es pensable una naturaleza cuya ley sea destruir la vida misma. Lo mismo ocurre con la promesa falsa, pues la universalidad de una máxima que diga que quien crea estar apurado puede prometer lo que se le ocurra y luego no cumplirlo haría imposible la promesa misma, es decir, sería una contradicción. Estos preceptos de Kant son correspondientes con los que en la tradición naturalista se consideraban intrínsecamente malos. Kant los considera fundamentalmente negativos; para él constituyen los deberes perfectos o de justicia.

Pero hay otros deberes cuya transgresión, al universalizarla -es decir, al convertirse en máximas-, no resulta lógicamente contradictoria, aunque sí éticamente contradictoria. Éstos son los deberes de obligación imperfecta o de beneficencia. Los ejemplos de Kant se refieren primeramente a dejar sin cultivo el propio talento, en el que la universalización de la máxima del obrar sí puede ser pensada sin contradicción aunque no puede ser querida sin contradicción, porque como ser racional el ser humano debe querer que se desenvuelvan en él todas sus facultades; en segundo término, no prestar ayuda a otros, que aun cuando fuera posible su universalización, el sujeto caería en contradicción en la emergencia de situaciones donde necesitara ayuda o compasión ajena.

De todo esto concluirá Kant que los deberes de obligación perfecta, es decir, aquellos cuya transgresión no puede ni siquiera ser pensada como máxima universal, no pueden tener excepciones, porque éstas no pueden concebirse ni pensarse como máximas universales de acción, esto es, como leyes naturales. Por tanto, estos deberes pueden afirmarse como absolutos. En Kant se recupera el antiguo concepto de ley natural intrínsecamente buena, cuya transgresión es intrínsecamente mala; claro que ahora por vía de la razón y no de la naturaleza.

\section{Crisis de la noción de deber}

Ahora bien, si dejamos por un momento en suspenso esta argumentación y centramos nuestra atención de manera general en el desarrollo de la época moderna, podemos advertir que, en relación con lo acontecido entre el siglo XVII y nuestros días, ha ocurrido una serie de cambios significativos en el ámbito de la ética y la moral. Lipovetsky, por ejemplo, señala que lo que venía ocurriendo paulatinamente era un proceso de secularización ética que, pese a su carácter laico (por 
el que buscó progresivamente emanciparse del espíritu religioso), conservó sin embargo una de sus figuras centrales: la del deber absoluto(4:11).

Hasta mediados del siglo anterior destacaron fuertemente la obligación y los deberes como base de sustentación de una ética social que prometía salvaguardar la integridad y la consistencia del orden secular, hasta el punto que la vida privada de los sujetos se vio copada por una amplia normatividad profundamente disciplinaria(5), emanada de la voluntad férrea de conculcar el despliegue individual, con el objeto de reforzar una unidad moral que se consideraba necesaria para la cohesión de la comunidad social(4).

Ahora bien, en el marco de este proceso de secularización de la moral, una lógica nueva viene a poner término a esta fase centrada en el deber incondicional y, de este modo, no sólo opera la escisión de la ética respecto del fenómeno religioso -signo distintivo de este nuevo momento en la secularización-, sino que además acaba en el ámbito social con su forma religiosa propiamente tal, vale decir, con el deber mismo.

Todo parece indicar que desde mediados del siglo XX se ha venido trasponiendo un umbral y hemos entrado en una época diferente, la del posdeber. Ello marcaría la diferencia de nuestra cultura ética, porque la nuestra es una sociedad que, lejos de exaltar los órdenes superiores, los desacredita; desvaloriza el ideal de abnegación, estimulando sistemáticamente los deseos inmediatos, la pasión del ego, la felicidad intimista y materialista. Son entonces los imperativos del bienestar subjetivo -antes que los de cualquier sacrificio- los que se expresan en modalidades de ética mínima y dan forma así a esta particular experiencia ética del presente. Ello porque la historia moderna ha producido una estructura hasta hace poco desconocida: la de la sociedad posmoralista(4:13).

Sin embargo, mientras el apostolado del deber decae ostensiblemente, asistimos a la vez a la reactualización general de la preocupación ética, al resurgimiento de las problemáticas y terapéuticas morales. Las ciencias biomédicas, los media, la empresa, están dominados por el discurso y la demanda ética. Nada queda fuera del tratamiento ético; es la hora de los himnos a la responsabilidad sin fronteras: la ecológica, la bioética, la humanitaria, la económica, como recuerda el pensador francés.
Es prudente aclarar, no obstante, que esta nueva emergencia ética no está animada en realidad por un imperativo que conduzca al abandono de los fines propios y a la sumisión al deber absoluto e incondicional, sino por un intento de amalgamar los valores y los intereses, los derechos individuales y las presiones de la vida social, económica y científica en un todo que sólo se muestra coherente con la propia incoherencia de nuestra época. Su objetivo específico, en el mejor de los casos, es poner límites al incremento progresivo de la lógica individualista de la sociedad actual -vector decisivo que conduce este complejo panorama-, mediante la legitimación de nuevas obligaciones colectivas que, por ejemplo, puedan conciliar el presente con el futuro, el desarrollo material con la vida humana, el avance del conocimiento con la libertad; en síntesis, todas aquellas contingencias históricas en las cuales, tarde o temprano, se presente la eventualidad de una contraposición excluyente entre lo técnico-económico y la vida misma, en cualquiera de sus múltiples expresiones.

El sentido actual de la responsabilidad correspondería al deber; claro que a un deber liberado de la noción de sacrificio. Ello porque, en realidad, la ética del presente no le vuelve la espalda a los valores individualistas, sino que expresa la culminación del carácter permisivo de la cultura liberal, en cuanto éste llega a constituirse finalmente en una amenaza para la seguridad y la libertad en nuestras sociedades.

Aun cuando el anterior sentido heroico del deber se esfuma a partir de esta disrupción histórica, no por ello el efecto ético disminuye su intensidad, puesto que, por el contrario, representa el factor más distintivo de la época actual. No hay contradicción o contraposición alguna en nuestro tiempo entre la cultura individualista que se propaga hoy en la sociedad posmoralista y sus corrientes antagónicas de moralismo creciente.

El porvenir se perfila en razón de este antagonismo, asumiendo, en un sentido, la intrincada forma actual de lo social y lo individual mediante recursos pluralistas y personalizados de comprensión de la moralidad; en otro, recluyendo dicha forma bajo el estricto marco de un nuevo dogmatismo ético y jurídico que es propuesto como alternativa al supuesto o previsible peligro de desintegración total de la voluntad moral. Sin embargo, aunque esta última perspectiva parezca una exageración infundada, no se puede dejar de reconocer que el desencadenamiento del así llamado posdeber prepara 
el terreno para la creciente proliferación de un individualismo extremo que no contempla regla.

\section{¿Deberes de los pacientes?}

A partir este marco, proponemos un ejercicio de reflexión en torno a los deberes de los pacientes, ya que el discurso acerca de los derechos constituye una expresión canonizada del pensamiento actual. Esta tarea no puede dejar de lado lo que se ha estado exponiendo en párrafos precedentes respecto del actual marco de fragmentación moral y la virtual disolución del sentido del deber como instancia absoluta y canónica de moralidad, lo que impulsa a los seres humanos a actuar de modo egoísta y a no reconocer reciprocidad alguna en la interacción humana.

No sería posible concretar, de igual manera a como se hace con los derechos, una Carta de deberes de los pacientes, más allá de aquellos específicamente establecidos en la legislación general que regula la prestación de servicios profesionales. Tampoco esperar que los pacientes asuman deberes perfectos o absolutos (manteniendo la terminología kantiana) frente a la relación sanitaria y contribuyan decidida y voluntariamente al propósito de la contraparte médica; porque debido a su desconocimiento técnico están privados de comprender el intrínseco sentido de la prescripción formulada por el especialista; o bien, porque por la carencia de educación preventiva respecto de situaciones de riesgo para la salud pueden incurrir en prácticas perniciosas que contradigan la voluntad médica y entorpezcan su eficacia. Esta sería, sin duda, una dificultad inicial y no menor.

Ello nos hace pensar entonces que el único deber que para el paciente se puede derivar de una relación biunívoca-como lo es el vínculo profesional-cliente-es uno de tipo imperfecto, que obliga siempre pero no para siempre. En este caso particular, obliga siempre porque hay un hecho de por medio que así lo impone: la situación misma de apremio en que sume el estado de enfermedad, que "obliga" (aunque no moralmente) a reclamar la atención. El posterior abandono del tratamiento, la renuencia a la administración de los medicamentos, la irregularidad de la asistencia a consultas programadas o cualquier otra circunstancia en la que el paciente actúe con total independencia e incluso abiertamente en contra de la voluntad del profesional sanitario repercute en definitiva sobre su propio ser de enfermo y no es posible suponer coacción alguna que lo haga desistir de sus actos, a no ser aquella que él mismo se imponga como resultado de su propio malestar o inconveniencia. En la esfera de la decisión personal y las consecuencias individuales no podría consignarse ningún deber perfecto u obligante.

Todo deber en este ámbito es por naturaleza imperfecto; obliga en el momento inicial, obliga a creer en la calidad técnica del profesional y a asumir los costos y ajetreos de la atención requerida, pero más allá de esto no puede obligar. Una vez superada la situación de emergencia inicial que motivó la consulta, saldada la deuda material contraída y restituido, aunque sea en su mínima expresión, el estado de normalidad, sólo si el paciente así lo desea, si así su voluntad lo admite, puede persistir en el reconocimiento del deber para con el médico o el servicio de salud correspondiente.

No obstante todo esto y a pesar de la veracidad que pudieran contener las precedentes afirmaciones, aún se puede pensar una mayor equidad en las responsabilidades de cada cual y una mayor reciprocidad de la relación entre médico y paciente. Todo ello en procura de la recuperación de la salud y también de una relación menos pasiva o paternalista, y más complementaria y consensual entre ambos términos.

La posibilidad de superar la resistencia al deber que puede experimentar el paciente -al suponer que su salud le pertenece y por tanto es sólo él quien debe decidir acerca de cuál será el grado de compromiso que establezca con el sistema sanitario, acercándose y alejándose cuando le parezca, siguiendo o abandonando el consejo o la terapia, favoreciendo o entorpeciendo el éxito de la intervención profesional con sus hábitos conductuales- tiene íntima relación con la definición esencial de la práctica médica como arte de curar más que como el despliegue de un dispositivo técnico y una racionalidad instrumental, porque no es posible tratar realmente a ninguna persona que se considere a sí misma como si fuera sólo un "caso", así como tampoco ningún médico puede ayudar a un individuo a superar una enfermedad grave o más o menos leve con sólo aplicarle la capacidad rutinaria de su disciplina.

La dimensión más profunda de la medicina, la única que puede hacer surgir desde la intimidad y la autenticidad del paciente el reconocimiento de deberes recíprocos que considere ineludibles, es aquella que lo reconoce en su ser diferente de los demás, sin llegar a 
estandarizarlo en patrones arbitrarios de objetividad y asumiéndolo desde la perspectiva de un saber-hacer que no se dirige sólo contra la enfermedad, sino que se orienta principalmente a su ser íntimo de enfermo.

El médico, para mantener su situación como médico, necesita saber limitar su poder como profesional. Debe ver más allá del "caso" a tratar para captar al individuo en la totalidad de su situación vital. Porque la noción del deber sólo puede surgir en una persona que ha sido educada en un marco de relaciones sustentadas en la confianza, en el placer de la responsabilidad, de la auténtica convivencia y la recíproca entrega de los seres humanos; en una persona que, incluso al adquirir en contra de su voluntad la calidad de paciente, continúe sintiéndose integrada a la totalidad de su vida. Quizás estas últimas no sean tareas que resulten del todo ajenas a la profesión médica y tal vez desde su misma perspectiva científico-técnica pueda avanzar paulatinamente hacia una verdadera comunidad de deberes con los pacientes.

\section{Referencias}

1. Gadamer H-G. El estado oculto de la salud. Barcelona: Gedisa; 1996: 45.

2. Delgado C. Hacia un nuevo saber. La bioética en la revolución contemporánea del saber. La Habana: Publicaciones Acuario, Centro Félix Varela; 2007: 115.

3. Jonas H. El principio de responsabilidad. Ensayo de una ética para la civilización tecnológica. Barcelona: Herder; 1995.

4. Lipovetsky G. El crepuisculo del deber. La ética indolora de los nuevos tiempos democráticos. Barcelona: Anagrama; 1996: 13.

5. Foucault M. Vigilar y castigar. Madrid: Siglo XXI; 1995.

Recibido: 23 de marzo de 2009

Aceptado: 12 de abril de 2009 